\title{
ESCRITA E ENSINO: PARA ALÉM DA GRAMÁTICA, COM A GRAMÁTICA
}

\section{(Writing and teaching beyond the grammar, with the grammar)}

\author{
Carlos A. M. Gouveia \\ (Faculdade de Letras da Universidade de Lisboa E \\ Instituto de Linguística Teórica e Computacional)
}

De todas as palavras fundamentais da área da ciência linguística, a palavra gramática talvez seja a que mais se tem prestado a confusões variadas ao longo dos tempos, em função dos múltiplos significados que lhe são atribuídos. Efectivamente, de gramática como estudo das regras que determinam o funcionamento de uma língua, até gramática como sistema de elementos e padrões que organiza a expressão linguística, passando por gramática como "um modelo de conhecimento da língua do falante-ouvinte $r$ epresentativo de uma dada comunidade linguística, reconhecendo-se-lhe várias componentes, que correspondem aos vários tipos de saber linguístico intuitivo de tal falante" (Faria et al. 1996: 14), várias são as acepções possíveis a considerar na construção da noção de gramática, a que depois se juntam novas significações em razão dos modificadores que com a palavra são usados (por exemplo, gramática descritiva, gramática formal, gramática escolar, gramática funcional, gramática tradicional, etc.).

A noção de gramática aqui adoptada é a de gramática enquanto conjunto de recursos para a produção de significado. Nesta acepção, a gramática é entendida como um instrumental de uso que explica o sistema e a estrutura da língua por conexão do texto, o que produzimos sempre que falamos, com o seu propósito social. Trata-se de uma visão da gramática como potencial de significação, desenvolvida no quadro de investigação e descrição gramatical da chamada linguística sistémico-funcional (Halliday 1978, 1993, 2004; Martin 1992; Martin and Rose 2002), em que o texto é tratado tanto como artefacto quanto como espécime: "não podemos explicar porque um texto significa o que significa, com todas as leituras e valores variados que lhe são atribuídos, a não ser relacionando-o com o sistema linguístico como um todo; e igualmente não podemos usá-lo como janela para o sistema, a não ser que compreendamos o que ele significa e porquê. 
Mas o texto tem um estatuto diferente em cada um dos casos: ou é visto como artefacto ou, ao invés, visto como espécime." (Halliday 2004: 3) ${ }^{1}$. Em ambos casos, o texto deverá ser explicável no quadro de uma descrição ("grammatics") que seja tão rica quanto a gramática ("grammar") ela própria.

A aplicabilidade desta noção de gramática ao ensino é de fácil demonstração, se se traçar uma distinção entre a chamada gramática tradicional (pré-chomskiana), a gramática formal e a gramática funcional (ambas pós-chomskianas) e se defender que a análise do discurso, em geral, e o modelo descritivo da linguística sistémico-funcional, em particular, representam tentativas de descrição do funcionamento da língua em função de um movimento de religação da gramática à retórica, numa conjunção disciplinar outrora existente e que urge recuperar: "Até muito recentemente, a gramática tradicional estava intimamente ligada ao estudo da retórica (...). Actualmente, a gramática e a retórica (para não falar da sofística) têm um mau nome, mas é importante compreender porque é que isso acontece. Christie $(1981,1990 \mathrm{~b})$ sugere que tal se deve, em parte, ao facto de a gramática tradicional ter sido dissociada da retórica nas escolas, pelo que perdeu o seu propósito; e uma vez afastado o propósito de ensinar os estudantes a falar e escrever mais eficientemente, a gramática também se banalizou." (Martin \& Rothery 1993: 138)².

Mas mesmo aceitando, como faço aqui, uma noção de gramática afastada das noções mais tradicionais de gramática como estrutura, como gramática da frase, conceptualizando-a, ao invés, como gramática da frase e do texto, um "conjunto de recursos para a produção de significado", por exemplo, ou como um sistema "organizado em torno do conceito de gramaticalização, em função do qual o significado é construído em redes de

\footnotetext{
${ }^{1}$ Vd. original inglês: "we cannot explain why a text means what it does, with all the various readings and values that may be $\mathrm{g}$ iven to it, except by relating it to the linguistic system as a whole; and equally, we cannot use it as a window on the system unless we understand what it means and why. But the text has a different status in each case: either viewed as artefact, or else viewed as specimen."

${ }^{2} \mathrm{Vd}$. original inglês: "Until relatively recently, traditional grammar was closed allied with the study of rhetoric (...). Curr ently, grammar and rhetoric (not to mention sophistry) have a bad name, but it is very important to understand why this is so. Christie $\left(1981,1990^{\mathrm{b}}\right)$ suggests that this is in part because traditional grammar became disassociated from rhetoric in schools, and so lost its purpose; and once the purpose of teaching students to speak and write more effectively was removed, the grammar became trivialised as well."
} 
contrastes relacionados" (Halliday, 2004: 10, 47) ${ }^{3}$, torna-se fundamental localizar tal noção relativamente à visão de língua que evoca.

É que, de facto, a noção de gramática aqui convocada tem por detrás uma visão de língua como realidade social e material, o que, mais do que a noção de gramática em si, ajuda a configurar e a distinguir processos, metodologias, teorizações e contextualizações fundamentais para o modo como queremos que a nossas crianças se relacionem com o seu instrumento de comunicação por excelência: a língua.

A situação do ensino da língua materna nas escolas portuguesas ao longo das últimas décadas, por exemplo, é reflexo da disjunção entre a gramática e a retórica nos estudos linguísticos e deveria ser alterada. Por exemplo, contrariamente ao que é comum fazer-se nas escolas em Portugal, a escrita, enquanto prática inegavelmente social, é mais bem explicada, ensinada e avaliada no quadro de teorias que encaram a língua como uma realidade fundamentalmente social e material (Beaugrande 1998; Hyland 2001), e a própria escrita não como um sistema secundário face à oralidade, como defendido em documentos oficiais do Ministério da Educação (cf. Sim-Sim et al. 1997: 24), mas como um sistema autónomo de funcionalidade complementar à oralidade ( $v d$. Halliday 2004: 7), usado na cultura em razão de motivações e contextos que de secundário nada têm e que nada devem à oralidade.

À luz de motivação de ordem sistémico-funcional, muitas são as orientações teóricas e metodológicas prevalecentes nos documentos oficiais de enquadramento, organização curricular e descrição do ensino de português no Ensino Básico (Curricula, Organização Curricular e Programas Escolares) que urge questionar. Em tais documentos, à reduzida importância atribuída a aspectos antropológicos e sociais das dinâmicas de uso da língua e à necessidade da sua aprendizagem em contexto escolar tem correspondido uma excessiva caracterização mentalista e psicolinguística dos fundamentos, processos e práticas do ensino/aprendizagem, muitas vezes sem uma afirmação clara da noção de língua e de linguagem que os motiva.

\footnotetext{
3 Vd. original inglês: "The perspective moves away from structure to consideration of grammar as system, enabling us to show the grammar as a meaning-making resource (...).", e ainda "A systemic grammar is one which is organized around this concept of grammaticalization, whereby meaning is construed in networks of interrelated contrasts."
} 
Nesse sentido, caracterizada a língua como uma realidade semiótica social (Halliday 1978), cada vez mais posta em contacto, relação e acção com outras modalidade semióticas, em processos multimodais e intermediais de significação que apelam à consideração de novas e multíplas literacias (The NLG 1996; Cope \& Kalantzis, ed. 2000; Unsworth 2002), a escrita deverá ser fundamentalmente encarada como um sistema de significação distinto da fala (oralidade), da qual tem sido vista, erradamente, como imitação, fixação ou espelho, apesar de desenvolvida funcionalmente ao longos dos séculos em complementaridade com ela, em contextos funcionais próprios (Halliday 1989, 1993).

Na consideração das linhas de reflexão atrás mencionadas, especial atenção tem de ser dada a aspectos de aprendizagem e de desenvolvimento da escrita, a partir de questões como: a que modelos de escrita são expostos na escola e fora dela os alunos dos diferentes níveis de ensino, isto é, que lêem os alunos no seu quotidiano? Qual o papel da língua materna e de outras línguas no quotidiano destes alunos e qual o papel da escrita nesse quotidiano? Que tipo de cultura de sala de aula e de escola é oficialmente identificada como potenciadora da aprendizagem e do ensino das competências da língua materna? Que competências de língua são dadas como adquiridas no final de cada ciclo do ensino básico e como correspondem as produções dos alunos dos diferentes ciclos a tais pressupostos / exigências, em termos de expressão lexicogramatical, de registo e de género? Como pode o ensino da língua materna ser apoiado por outras disciplinas escolares e ser simultaneamente suporte de aprendizagem nessas disciplinas? Como é tratada a questão da literacia nos curricula escolares (Christie \& Misson, eds. 1998)? Que aspectos de multiliteracia são considerados em termos de desenvolvimento da escrita, quer do ponto de vista dos modos e meios (multimodalidades e intermedialidades), quer do ponto de vista da formalidade/informalidade (géneros escolares e géneros informais dos tempos livres)? Como apoiam as escolas o ensino da literacia relativa às paisagens textuais dos alunos, i. e., relativa ao ambiente textual formal e informal do s alunos? Quais os critérios de avaliação de desempenho identificados, sistematizados e disponibilizados pelo Ministério da Educação para avaliação das produções textuais dos alunos? Que formação é disponibilizada aos professores que potencie a avaliação de desempenho e a identificação de indicadores de desenvolvimento da escrita?

E-mail: carlos.gouveia@fl.ul.pt 


\section{REFERÊNCIAS}

Beaugrande, R. de (1998): Performative speech acts in linguistic theory: The rationality of Noam Chomsky. Journal of Pragmatics 29: 765-803.

Christie, F. \& R. Misson, eds. (1998): Literacy and schooling. London: Routledge.

Cope, B. \& M. Kalantzis (2000): Multiliteracies: Literacy Learning and the Design of Social Futures. London: Routledge.

FARIA, I. H. et al. (1996): Introdução à Linguística: Geral e Portuguesa. Lisboa: Editorial Caminho.

Halliday, M. A. K. (1978): Language as Social Semiotic: The Social Interpretation of Language and Meaning. London: Edward Arnold.

Halliday, M. A. K. (1989): Spoken and written language. $2^{\text {nd }}$ Ed. Oxford: Oxford University Press.

Halliday, M. A. K. (1993): Towards a Language-Based Theory of Learning. Linguistics and Education, 5: 93-116.

Halliday, M. A. K. (2004) An Introduction to Functional Grammar. $3^{\text {nd }}$ Ed. revised by C. M. I. M. Matthiessen. London: Arnold.

HyLAND, K. (2001): Teaching and Researching Writing. London: Longman.

Martin, J. R, \& D. Rose (2002): Working with Discourse: Meaning beyond the Clause. London: Continuum.

Martin, J. R. (1992): English text: System and Structure. Amsterdam: John Benjamins Publishing Co..

Martin, J. R. \& J. Rothery (1993): Grammar: Making Meanings in Writing. In Cope, B. \& M. Kalantzis, eds.: The Powers of Literacy: A Genre Approach to Teaching Writing. London: The Falmer Press: 137-153.

Sim-Sim, Inês et al. (1997): A língua materna na Educação Básica: Competências Nucleares e Niveis de Desempenho. Lisboa: Ministério da EducaçãoDepartamento da Educação Básica.

The New London Group (1996): A Pedagogy of Multiliteracies: Designing Social Futures. Harvard Educational Review, 66 (1): 60-92.

Unsworth, L. (2002): Changing dimensions of school literacies. Australian Journal of Language and Literacy, 25 (1): 62-77. 